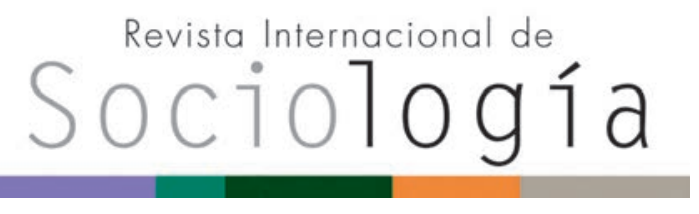

Revista Internacional de Sociología RIS

vol. 77 (1), e119, enero-marzo, 2019, ISSN-L:0034-9712

https://doi.org/10.3989/ris.2019.77.1.17.126

\section{LA DISTRIBUCIÓN DEL TIEMPO DISCRECIONAL EN ESPAÑA}

\author{
Pedro M. Rey-Araújo \\ Universidade de Santiago de Compostela \\ pedrom.rey@rai.usc.es \\ ORCID iD: https://orcid.org/0000-0002-0008-4633
Melchor Fernández FeRnández
Universidade de Santiago de Compostela
melchor.fernandez@usc.es \\ ORCID iD: https://orcid.org/0000-0002-6255-2033
}

Cómo citar este artículo / Citation: Rey-Araújo, P. M. y M. Fernández-Fernández. 2019. "La distribución del tiempo discrecional en España”. Revista Internacional de Sociología 77(1):e119. https://doi.org/10.3989/ ris.2019.77.1.17.126

\begin{abstract}
RESUMEN
El presente artículo aplica la metodología del tiempo discrecional al caso de la sociedad española. Mientras que la noción de tiempo libre en los estudios sobre usos del tiempo es generalmente construida como el remanente tras sustraer el tiempo efectivamente empleado en el empleo, el trabajo doméstico y los cuidados personales, el tiempo discrecional usa en su lugar el mínimo tiempo que es necesario emplear en las rúbricas indicadas. Al emplear estándares de necesidad en lugar de elecciones concretas, se configura como una aproximación más adecuada a la autonomía temporal de la que disfrutan los individuos y, por extensión, a su respectivo bienestar individual. Con el objetivo de desvelar las diversas segmentaciones existentes en la sociedad española en lo tocante al tiempo, el énfasis recaerá primordialmente en las intersecciones existentes entre las relaciones de género y la clase socioeconómica de origen.
\end{abstract}

\section{Palabras Clave}

Autonomía temporal; Clase; Género; Tiempo; Tiempo libre.

\section{THE DISTRIBUTION OF DISCRETIONARY TIME IN SPAIN}

Copyright: (C) 2019 CSIC. Este es un artículo de acceso abierto distribuido bajo los términos de la licencia de uso y distribución Creative Commons Reconocimiento 4.0 Internacional (CC BY 4.0).

Recibido: 07/09/2017. Aceptado: 18/05/2018

\section{KEYWORDS}

Class; Free time; Gender; Temporal autonomy; Time. 


\section{INTRODUCCIÓN}

El presente artículo se propone aplicar la metodología del tiempo discrecional (Goodin et al. 2008; Rice, Goodin y Parpo 2006; Goodin et al. 2005) al caso español. La noción de tiempo discrecional guarda relación con el concepto de tiempo libre, aunque diverge de esta significativamente. El tiempo libre, tal y como es generalmente conceptualizado en los estudios relativos a los usos del tiempo, se construye como el tiempo restante tras sustraer al tiempo disponible la cantidad empleada respectivamente en el empleo, el trabajo doméstico, y los cuidados personales. El tiempo discrecional, en contraposición, se construye al sustraer el mínimo tiempo que es estrictamente necesario emplear en dichas tres categorías. Al hacer referencia a estándares de necesidad en lugar de a decisiones concretas por parte de los individuos sobre cómo emplear su propio tiempo, se presenta como una aproximación más adecuada a la disponibilidad temporal de los individuos, así como a la presión temporal que estos, en última instancia, soportan. Al sintetizar indicadores de índole tanto temporal como monetaria, el tiempo discrecional se presenta así como una aproximación cualitativamente diferente a la problemática del bienestar individual en relación con aquellas otras generalmente empleadas (Shippen 2014).

El presente artículo ofrece dos contribuciones principales. En primer lugar, dicha metodología ha sido aplicada, hasta el momento, a países representativos de los tres regímenes de bienestar identificados por Esping-Andersen (1990; 1999), con singular atención a los efectos sobre la autonomía temporal derivados de las relaciones de género subyacentes, así como de los diferentes tipos de hogar. El presente artículo expande el alcance empírico del marco teórico en dos direcciones: por un lado, al aplicarlo al caso español, un representante arquetípico del régimen de bienestar Mediterráneo (Karamessini 2008; Ferrera 1996; Saraceno 1994); por otro lado, al situar las relaciones de clase en el centro del análisis de las segmentaciones temporales. En segundo lugar, ofrece una nueva contribución a los estudios relativos a las desigualdades y segmentaciones imperantes en el seno de la sociedad española, al emplear simultáneamente información de índole monetaria y temporal, prestando especial atención a las ocasionadas por la intersección entre las relaciones de género y clase socioeconómica, (e.g. Gómez Serrano, Molero Simarro, y Buendía 2016; Prieto 2015).

\section{AutonOMÍA TEMPORAL Y TIEMPO LIBRE}

Las sociedades contemporáneas se encuentran atravesadas por diversas desigualdades de índole socioeconómica que distribuyen de forma asimétrica los frutos resultantes de su participación en los ordenamientos sociales imperantes. Debido, por un lado, a la ausencia de fuentes estadísticas fiables respecto a los usos del tiempo por parte de los individuos $y$, por otro, al desarrollo a lo largo del siglo XX de los actuales sistemas de contabilidad nacional, dichas desigualdades han sido mayormente medidas, en el campo de las ciencias sociales, a través de las desigualdades existentes en relación con las distribuciones de renta y riqueza. Sin embargo, es razonable suponer que dichas desigualdades, más allá de sus reflejos monetarios, han de tener sus correspondientes correlatos en los diversos usos temporales que realizan los individuos, así como en los diferentes grados de disponibilidad temporal de los cuales los mismos disfrutan.

Los estudios de índole cuantitativa sobre la distribución social de los tiempos y sus respectivos usos en la sociedad española toman como punto de partida, en su inmensa mayoría, la Encuesta de Empleo de Tiempo (EET) realizada por el Instituto Nacional de Estadística (INE). No obstante la diversidad de sus respectivas motivaciones, dichos estudios suelen poseer ciertas características en común. Por un lado, la metodología predilecta ha sido la distribución cuantitativa de los tiempos en un día promedio, mediante una agrupación de las diversas actividades recogidas en cuatro grandes conjuntos: tiempo empleado en los cuidados personales, en el trabajo doméstico y de cuidados, en el trabajo remunerado $y$, finalmente, en el ocio o actividades de tiempo libre.

Por otro lado, el foco ha recaído predominantemente sobre la división sexual del trabajo doméstico, siendo la española una de las más asimétricas en el contexto europeo. Esta ha sido analizada en relación con las bajas tasas de fertilidad que caracterizan a la sociedad española (Gálvez-Muñoz, RodríguezModroño y Domínguez-Serrano 2011); las inferiores tasas de participación laboral femenina respecto a la media del entorno comunitario (Gálvez-Muñoz, Rodríguez-Modroño y Domínguez-Serrano 2011); la satisfacción subjetiva con el tiempo de ocio disfrutado (Gimenez-Nadal y Sevilla 2011); los motivos para su resiliencia o pervivencia en el tiempo (GimenezNadal y Sevilla 2014), o los efectos que acarrea sobre la segmentación del mercado laboral a través de la diferente disponibilidad temporal entre los géneros (Prieto y Perez de Guzmán 2013). Ciertamente, la magnitud de la división entre los géneros es considerable, sus causas numerosas y sus ramificaciones múltiples. De forma representativa, Callejo y Prieto concluyen: "No sólo se da una clara diferencia entre géneros, sino que (...) desde el punto de vista de la distribución de los tiempos de las actividades, esa diferencia es superior a las originadas por otros criterios de jerarquización social, como el de origen étnico o de estratificación de clase socioeconómica" (Callejo y Prieto 2015: 58).

Sin embargo, esta relativa sobrerrepresentación de la dimensión de género para aprehender las divi- 
siones sociales en torno al uso y disposición de los tiempos encuentra su correlato en una cierta infrarrepresentación en dichos estudios de la posición diferencial que los diversos agentes ocupan en la organización del sistema productivo español. Un hecho singularmente significativo en tanto que, en el modelo económico español actual, el tiempo juega un papel crucial en su funcionamiento, debido a la sobrerrepresentación en el mismo de sectores económicos caracterizados por bajos niveles de productividad laboral y que, sin embargo, demandan una alta disponibilidad temporal por parte de los trabajadores (Rey-Araújo 2016). Además, el tamaño medio singularmente reducido de las plantas productivas, los bajos niveles de representación sindical en relación con el contexto europeo, así como los elevados niveles de desempleo y de temporalidad laboral, generan un modelo social y productivo que tiende a exacerbar el influjo de los tiempos y ritmos de mercado sobre el resto de tiempos sociales (Banyuls et al. 2009). Con tal motivo, es de esperar que las diferencias relativas al bienestar temporal disfrutado por los individuos muestren un comportamiento similar a aquellas relacionadas con las variables monetarias al uso. Por lo tanto, cabría pensar que, al igual que las diferencias en torno a los niveles de renta o riqueza se relacionan íntimamente con la clase socioeconómica de origen, el equivalente temporal de las mismas lo constituiría la magnitud y cantidad de tiempo libre del que dichos agentes disfrutan. Es decir, bajo este razonamiento las clases privilegiadas serían inherentemente clases ociosas (Veblen 2004).
Sin embargo, a raíz de los resultados presentados en el seminal estudio de Gershuny (2000), tal asociación parecería no corresponderse ya con la vivida en nuestros días. Débase esta situación al sistema de incentivos que permea toda sociedad capitalista (Schor 1994); a un entendimiento de la ocupación como símbolo de distinción (Gershuny 2005), o a la creciente desigualdad en términos de ingresos (Bowles y Park 2005; Freeman y Bell 2001), por citar algunas explicaciones ofrecidas al respecto, lo cierto es que la magnitud del tiempo libre disfrutado por los individuos, al menos en la forma en que es generalmente computado, no parece guardar una relación directa con aquellas dimensiones socioeconómicas a través de las cuales se suele incorporar al análisis la clase social de origen y/o pertenencia.

El caso español no constituye una excepción. Se presentan a continuación los datos relativos al tiempo libre disfrutado en un día promedio por hombres y mujeres, de 18 a 65 años, obtenidos a partir de la EET 2009/10. Si se acepta el nivel educativo logrado por la persona como una válida aproximación a la clase socioeconómica de origen, los datos obtenidos (ver Figura 1) parecen confirmar la hipótesis defendida por Gershuny (2000), pues se observa una relación inversa entre el nivel educativo obtenido y el tiempo libre disfrutado en un día promedio. Además, para cada uno de los niveles considerados, la existencia de una divergencia clara en torno al género resulta patente, las mujeres disfrutando sistemáticamente de menos tiempo libre que sus homólogos masculinos.

Figura 1.

Tiempo libre en un día promedio en función del nivel educativo

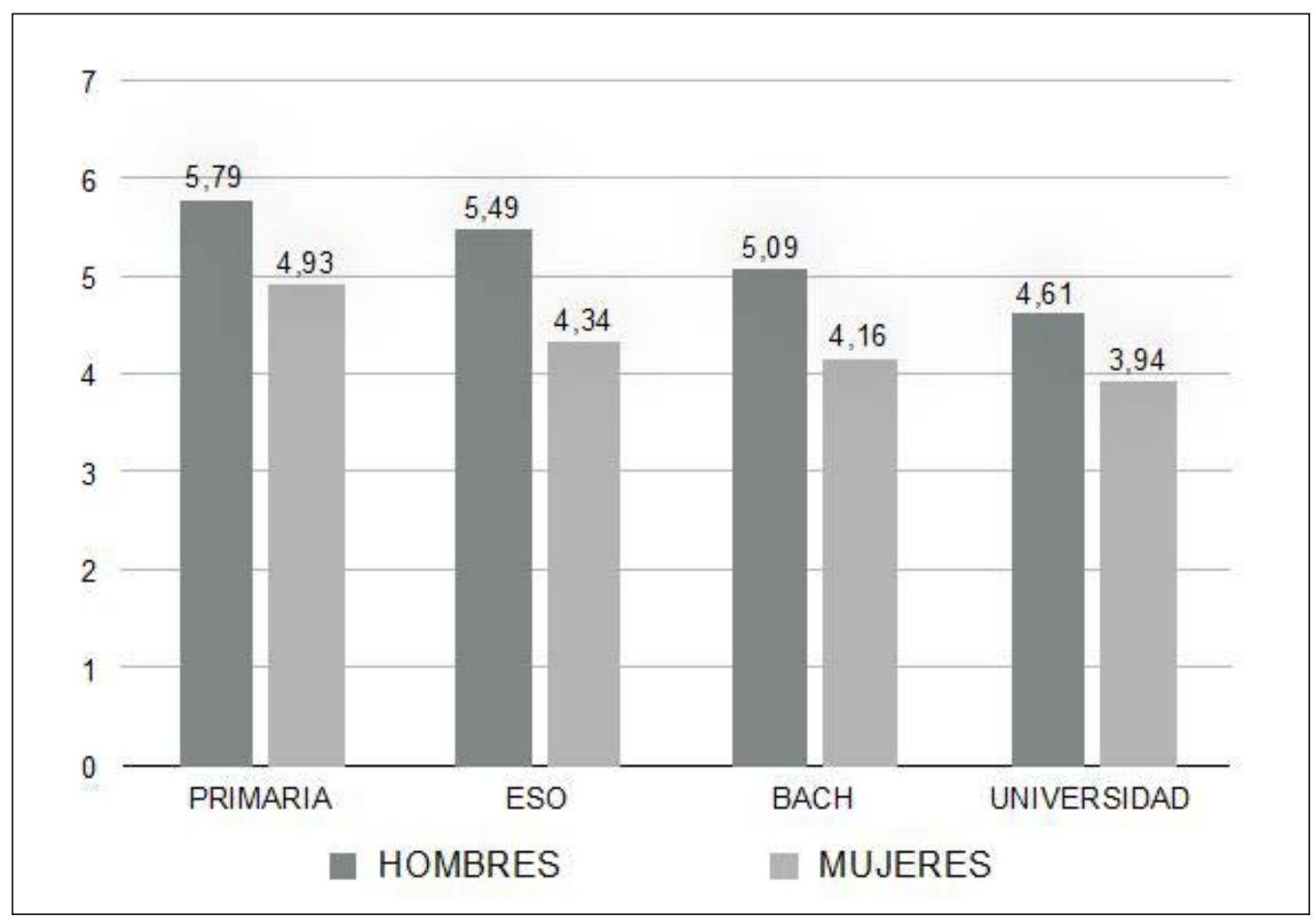


Una manera alternativa de aproximarnos a la clase socioeconómica, íntimamente ligada con la anterior aunque no análoga, la constituye el nivel de ingresos mensuales derivados del empleo principal. El bajo nivel de desagregación de las variables relativas a la renta ofrecido en la EET impide mostrar un análisis más pormenorizado. Sin embargo, resulta patente que los datos contenidos en la Figura 2 no revelan una relación entre clase socioeconómica y tiempo libre similar a la presentada en la figura anterior.

Con relación a los hombres, las variaciones observadas en lo tocante al tiempo libre disfrutado con respecto al nivel de ingresos son significativamente reducidas. En los tres primeros tramos de renta considerados se observa una paulatina reducción junto con un pequeño repunte en el último segmento. Con relación a las mujeres, la relación observada es prácticamente la inversa. Un paulatino incremento en los tres primeros tramos culmina con un retroceso en el último que sitúa a los dos niveles extremos a la par. Al contario del caso anterior, donde la clase socioeconómica fue medida a través del nivel educativo alcanzado por los individuos, para ninguno de los dos sexos parece confirmarse la relación entre tiempo libre y clase socioeconómica inferida por Gershuny (2000).

El análisis presentado hasta el momento no pretende ser exhaustivo en ningún caso, mas permite plantear una serie de interrogantes. Si la distribución relativa del tiempo libre en función de diversas cate- gorías, a través de las cuales parece razonable inferir la clase socioeconómica a la cual pertenecen los individuos, no muestra diferencias significativas entre las mismas o, al menos, no en el sentido esperado, cabría pensar pues que el tiempo libre podría no constituir un equivalente temporal adecuado de los niveles de renta o riqueza, en el ámbito monetario, para evaluar el bienestar relativo de los individuos. No obstante, resulta asimismo razonable presuponer que aquellos individuos que disfrutan de un mayor bienestar individual deberían gozar también de una mayor autonomía sobre su propio tiempo, por lo que la distribución cuantitativa de los tiempos, agrupados estos en cuatro grandes agregados, podría no ser la metodología adecuada para medir la discrecionalidad con la cual los individuos gobiernan su propio tiempo, es decir, para evaluar el tiempo como recurso mediante el cual satisfacer diversas necesidades.

\section{EL TIEMPO DISCRECIONAL EN OPOSICIÓN AL TIEMPO LIBRE}

Con el objetivo de discernir los diversos grados de necesidad $u$ obligatoriedad que se encuentran detrás de los usos del tiempo declarados por los individuos, la noción de tiempo discrecional (Goodin et al. 2008; Rice, Goodin, y Parpo 2006; Goodin et al. 2005) surge en contraposición a la de tiempo libre. Esta última, generalmente, se obtiene tras sustraer a las 24 horas que comprende un día (o 168 semanales) el tiempo dedicado a las diversas actividades

Figura 2.

Tiempo libre en un día promedio en relación con el nivel de ingresos

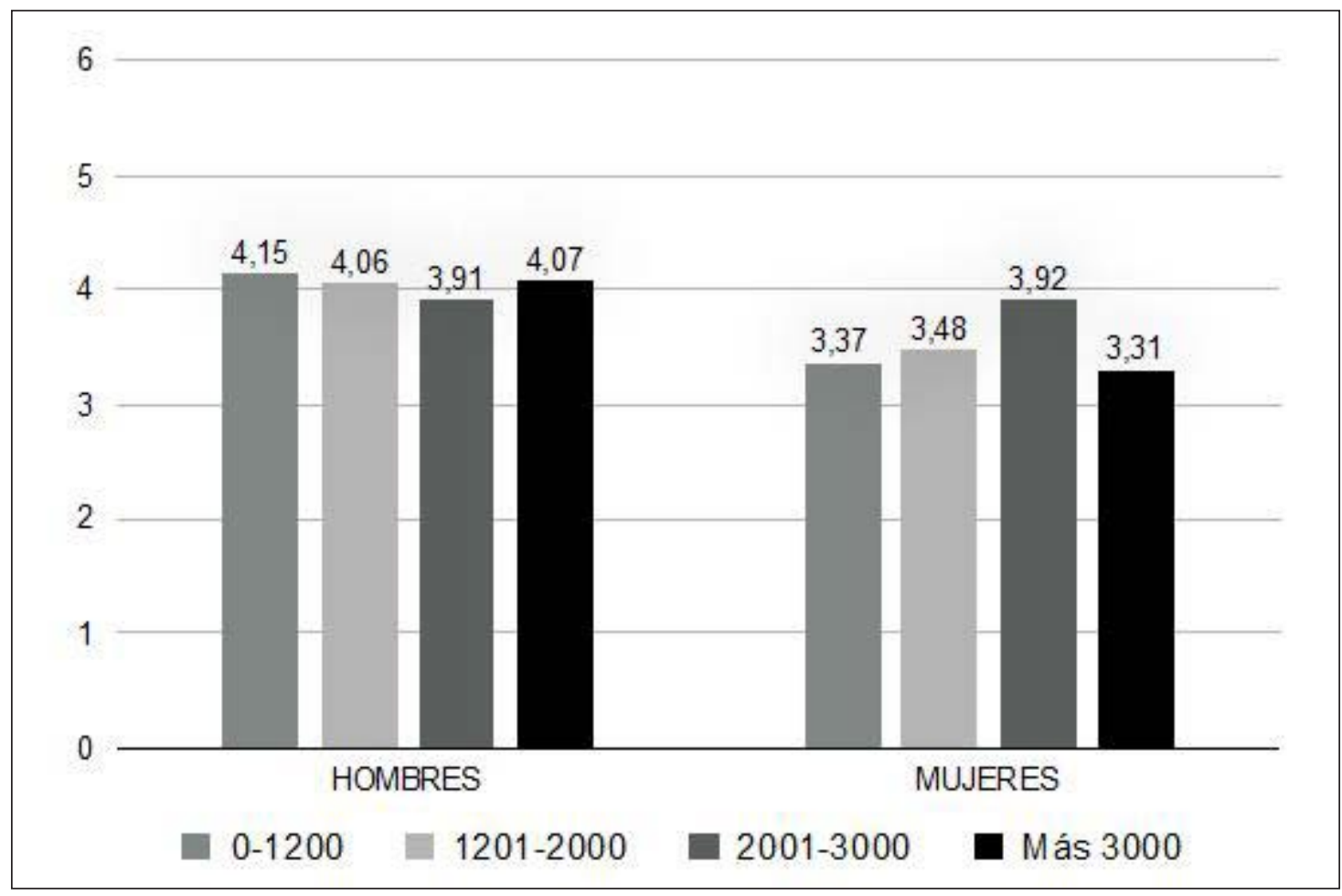

RIS [online] 2019, 77 (1), e119. REVISTA INTERNACIONAL DE SOCIOLOGÍA. ISSN-L: 0034-9712 
agrupadas bajo las rúbricas de cuidados personales, trabajo remunerado y trabajo no remunerado en el hogar. Ciertamente, la reproducción de la vida, tanto individual como socialmente, implica que determinadas actividades son de obligada realización (i.e. ciertas horas de sueño, un mínimo de aseo personal, comer, ofrecer cuidados a aquellos que los requieren). Además, en toda sociedad capitalista la mayoría de la población ha de vender una porción de su tiempo para así poder adquirir los bienes y servicios necesarios para poder desarrollar las actividades arriba mentadas. Sin embargo, nada impide, generalmente, que dichos individuos dediquen un tiempo mayor del estrictamente necesario a tales actividades. La inmensa mayoría, efectivamente, lo hace.

La principal intuición subyacente al concepto de tiempo discrecional es que cada persona, una vez alcanzado el mínimo de tiempo que es necesario dedicar a cada una de dichas actividades con el objetivo último de meramente subsistir, puede dedicar a las mismas más tiempo del estrictamente necesario. Mientras que el tiempo libre sería el resultado de sustraer el tiempo efectivamente empleado en cada uno de los tres principales grupos de actividades (cuidados personales, trabajo remunerado y trabajo no remunerado en el hogar), el tiempo discrecional sería el resultado de sustraer el mínimo tiempo que resulta necesario emplear en las mismas. El segundo aspira a cuantificar el tiempo que no está regulado por consideraciones de estricta necesidad, es decir, aquel con el que contarían los individuos una vez llevadas a cabo aquellas tareas cuya realización es innegociable para alcanzar la mera subsistencia; mientras que el primero se correspondería con una elección concreta dentro de los límites impuestos por aquella, pudiendo estos mismos individuos dedicar a cada tarea un tiempo superior al estrictamente imprescindible.

Por ejemplo, dos individuos pueden declarar encontrarse igualmente ocupados, en el sentido de disponer del mismo tiempo para aquellas actividades no ligadas ni al empleo ni a los cuidados $y$, sin embargo, disponer efectivamente de distintos grados de autonomía sobre su propio tiempo, pues parece razonable presumir que, aunque aquellos que disponen de un título universitario declaren disponer de menos tiempo libre que aquellos que no han llegado a alcanzar la educación secundaria, el grado de necesidad implícito en sus respectivas situaciones de partida sería en última instancia distinto. Es decir, uno podría verse obligado a emplear la mayor parte de su tiempo para meramente garantizar un nivel mínimo de subsistencia a los miembros de su familia, mientras que otro podría emplearlo por razones de estatus, prestigio o mera elección individual. Desde la perspectiva del diseño de las políticas públicas resulta crucial discernir qué grupos de individuos sufren carencia de tiempo libre por cuestiones de estricta necesidad y qué grupos la sufren por razones que escapan a la misma.

La metodología del tiempo discrecional aspira precisamente a cuantificar el grado de autonomía del que disfrutan los individuos abstrayéndose de las elecciones individuales que los mismos realizan. El grado de necesidad al que están sometidos los individuos está altamente condicionado por diversos factores estructurales que escapan a su control directo, tales como el género, el origen étnico, la clase socioeconómica o el tipo de hogar. Dichos factores afectan en distinto grado a la disponibilidad temporal de los agentes implicados, reforzando o atenuando las desigualdades existentes en otros ámbitos. En el presente artículo, el análisis recaerá primordialmente sobre las desigualdades resultantes de la intersección entre las relaciones de género y las de clase. Al centrarse explícitamente en los grados de necesidad a los que están sometidos los individuos en función de su posición concreta en el ordenamiento social, otorgando una cuantificación temporal a los mismos, el tiempo discrecional representa una aproximación más concreta a la problemática del bienestar individual que el tiempo libre, pues no es posible inferir, a partir de la magnitud declarada de este último, las restricciones estructurales que operan sobre cada individuo. Asociando bienestar y autonomía (Shippen 2014), tal y como se hace en los estudios relativos a renta y riqueza, defendemos que de un mayor tiempo discrecional sí puede inferirse un mayor bienestar individual, mientras que, en el caso del tiempo libre, tal asociación no puede ser trazada por los motivos arriba expuestos. Además, al combinar simultáneamente información de índole tanto temporal como monetaria, se ofrece una perspectiva cualitativamente distinta en relación con aquéllas centradas únicamente en una de las dos categorías. Antes de presentar un análisis detallado de la metodología empleada para calcular el tiempo discrecional del que goza cada individuo, el siguiente apartado introduce las bases de datos empleadas, así como la muestra final con la cual hemos operado.

\section{BASES DE DATOS Y RESTRICCIONES DE LA MUESTRA}

Desgraciadamente, la información relativa a renta y riqueza contenida en la Encuesta de Empleo del Tiempo brilla por su ausencia, por lo que para generar las variables arriba indicadas es necesario combinar la información contenida en la Encuesta de Empleo del Tiempo 2009-10 (INE 2011a) y la Encuesta de Condiciones de Vida 2010 (INE 2011b), ambas realizadas por el INE. Las variables necesarias para calcular el tiempo necesario en cuidados personales y el tiempo necesario en el trabajo doméstico provienen íntegramente de la primera, mientras que todas las variables monetarias requeridas para el cálculo del tiempo necesario en el trabajo remunerado fueron obtenidas a través de la segunda. 
La información relativa a los usos del tiempo se ha obtenido a partir de los microdatos de la Encuesta de Empleo del Tiempo correspondiente a los años 2009-10, la última edición disponible. Concretamente, hemos empleado la información contenida en el diario de actividades, el cual fue cumplimentado por todos los miembros mayores de 10 años residentes en los hogares que forman parte de la muestra. Dicho diario recoge todas las actividades realizadas por los individuos en cuestión en un día completo, dividiéndose el mismo en fragmentos de 10 minutos cada uno, indicando para cada uno de estos cuál era la actividad principal que estaban realizando; cuál la actividad secundaria, en caso de haberla, y en compañía de quién fueron realizadas. En total figuran 19 295 diarios de actividades, de los cuales 17859 se corresponden con individuos en edad adulta.

Por otra parte, la información relativa a las fuentes de renta monetaria ha sido obtenida a través de los microdatos de la versión de 2010 de la Encuesta de Condiciones de Vida, donde se incluye información relativa a 13597 hogares. Pese a haber ediciones posteriores disponibles, la edición de 2010 ha sido seleccionada con el objetivo de tornarla conmensurable con la información de índole temporal extraída de la EET. Concretamente, se ha obtenido la información necesaria para calcular los respectivos salarios por hora de las personas incluidas en la muestra, los impuestos pagados y las diversas prestaciones públicas recibidas (desempleo, jubilación, invalidez...).

En relación con la muestra con la cual finalmente operamos, dado que es estrictamente necesario disponer de información relativa al empleo remunerado, se ha restringido la misma a aquellos hogares compuestos bien por un adulto, el cual disponga de un empleo remunerado, o bien por una pareja heterosexual dentro de la cual al menos un integrante participe activamente en el empleo. Todos los adultos de los hogares considerados han de situarse en el tramo central de su vida adulta (25-55 años), con el objetivo de poder aprehender con mayor precisión la dimensión temporal de los conflictos que surgen alrededor de la conciliación entre el empleo y las responsabilidades de cuidados. Hemos excluido de la muestra, a su vez, a aquellos hogares con algún adulto a mayores de los arriba indicados, pues en dichos casos resulta complicado determinar cómo distribuir las responsabilidades relativas por el trabajo de cuidados entre los mismos. Finalmente, la muestra resultante consta de 6139 adultos entre 25 y 55 años (3018 hombres y 3031 mujeres), distribuidos en 3462 hogares distintos (785 hogares formados por un único adulto; 1053 hogares constituidos por dos adultos, de los cuales solamente uno participa en el empleo, y 1624 hogares donde los dos adultos incluidos participan del trabajo remunerado). A continuación, presentamos brevemente cómo se han calculado las variables intermedias necesarias para obtener el tiempo discrecional disfrutado por cada uno de los adultos integrantes de la muestra.

\section{Conceptualizar el tiempo discrecional}

Para establecer un criterio de necesidad, tanto respecto al tiempo como a la renta, existen dos rutas principales. La primera es trabajar con indicadores absolutos de necesidad, esto es, definir la cantidad de tiempo que resultaría biológicamente necesario emplear para reproducir la propia vida, sin estrictamente ligarla a las convenciones o normas sociales imperantes en la sociedad en cuestión (Bittman 2011). La segunda posibilidad, común en los estudios relativos a la pobreza monetaria, es establecer criterios relativos de necesidad (Goodin et al. 2011). Esta es la opción seguida por Goodin et al. (2005), Goodin et al. (2008) y Rice, Goodin y Parpo (2006), a la cual aquí nos adherimos. Dado que todos los individuos necesariamente habitan un ordenamiento social concreto, el empleo de criterios relativos de necesidad permite dilucidar las lógicas de segregación y jerarquización que operan en el seno de lo social.

Inevitablemente, establecer criterios relativos implica introducir una cierta discrecionalidad por parte del analista. En los estudios relativos a la pobreza monetaria, la convención imperante consiste en diseñar umbrales de pobreza que tomen como referencia la distribución efectiva de los recursos en la sociedad a la cual se refieren (generalmente, el $50 \%$ o $60 \%$ de la mediana). De forma análoga, los respectivos estándares de necesidad relativos a los cuidados personales y al trabajo doméstico tomarán como referencia la distribución efectiva de dichos tiempos en la sociedad española. Con el objetivo de favorecer la comparabilidad internacional de los datos obtenidos en el presente estudio con aquellos recogidos en Goodin et al. (2008), la metodología aquí adoptada sigue a aquella en la medida de lo posible, separándose de la misma cuando es estrictamente necesario. A continuación, presentamos brevemente el modo en el cual se ha procedido a calcular, respectivamente, el tiempo necesario en cuidados personales, el tiempo necesario en el trabajo doméstico y el tiempo necesario en el trabajo remunerado. ${ }^{1}$

La información necesaria para el cálculo tiempo necesario en cuidados personales ha sido obtenida únicamente a partir de la EET. Tomando como referencia a todos los adultos entre 20 y 65 años incluidos en la muestra, se ha calculado la mediana de la distribución resultante, tomando en consideración todas las actividades que el INE agrupa bajo dicha rúbrica (p.ej. comer, dormir, aseo personal). El umbral de necesidad ha sido situado en el $80 \%$, en lugar del 50\% empleado para las categorías restantes, pues la elección del segundo habría implicado que el umbral resultante superase ligeramente 
las 5 horas/día, tiempo en el cual resulta difícil de concebir que puedan cumplimentarse las necesidades mínimas de sueño y aseo, aun empleando los límites biológicos más estrictos. Una vez calculado el valor resultante, se ha asignado el mismo valor a todos los individuos de la muestra, dado que son actividades cuya distribución poblacional es singularmente homogénea.

La información requerida para el cálculo del tiempo necesario en el trabajo doméstico ha sido igualmente obtenida de la EET de forma íntegra. De nuevo, los respectivos umbrales de pobreza han sido calculados tomando en consideración a toda la población entre 20 y 65 años incluida en la EET. Con el objetivo de aprehender las diferentes demandas temporales derivadas de los diversos tamaños de hogar, se ha dividido el total declarado por los adultos presentes en cada hogar por una escala de equivalencia definida por la raíz cuadrada del número de integrantes del mismo. Una vez calculado dicho total equivalente, la muestra se ha subdividido en cuatro grupos con el objetivo de aprehender las diferentes responsabilidades derivadas del cuidado de los niños, tomando en consideración, por un lado, la presencia o no de hijos menores de 5 años en el hogar $y$, por otro, la presencia o no de un adulto en el hogar que no participe en el empleo remunerado (por lo tanto, susceptible de aliviar la responsabilidad de cuidados del adulto empleado, en caso de haberlo). Finalmente, se ha calculado un umbral de necesidad diferente para cada uno de los cuatro grupos, tomando como referencia el $50 \%$ de la mediana de la distribución resultante.

Una vez calculados los respectivos umbrales de necesidad para los cuatro grupos arriba indicados, ha sido preciso determinar cómo dicha carga ha de ser repartida entre las personas integrantes de los hogares recogidos en la muestra restringida con la cual operamos. Por un lado, no se le ha asignado ninguna responsabilidad al respecto a los menores presentes en cada hogar, tal y como recomiendan Goodin et al. (2008: 49), pues se entiende que, al hablar de responsabilidad por haber alcanzado un mínimo socialmente aceptado, la misma debe recaer enteramente sobre los adultos integrantes del hogar. Finalmente, para cada adulto se ha calculado la proporción en la cual efectivamente contribuyen a realizar el trabajo doméstico, según lo declarado en la encuesta. Dichos ratios han sido empleados para distribuir el umbral de necesidad correspondiente a cada hogar entre los adultos presentes en el mismo, siendo la cantidad resultante su respectivo tiempo necesario en el trabajo doméstico. Ciertamente, cabría pensar que, al reducir significativamente el volumen de trabajo doméstico que es preciso desarrollar, habría espacio para alterar significativamente las muy rígidas convenciones de género al respecto imperantes en la sociedad española. Sin embargo, inferir cómo el reparto de tareas en el hogar habría cambiado al reducir su volumen total se sitúa fuera del alcance de este artículo. El hecho de que las convenciones sociales en torno al género sean en última instancia contingentes y, por lo tanto, estén sujetas a modificación, no implica que, para las mujeres españolas, dichas convenciones tengan un fuerte carácter de obligatoriedad al situarse significativamente fuera de su alcance.

Finalmente, el tiempo necesario en el trabajo remunerado es aquel que permita al hogar alcanzar el umbral de pobreza, definido este como se acostumbra, es decir, como el $50 \%$ de la renta equivalente mediana en España, empleando como escala de equivalencia la raíz cuadrada del número de miembros del hogar. Como indicábamos anteriormente, la EET no ofrece información sobre la renta de los hogares con el grado de detalle requerido por el ejercicio aquí propuesto, por lo que es preciso recurrir a la información contenida en la ECV para el desarrollo de este apartado. Una vez fijado el nivel de renta que cada hogar ha de alcanzar para que sus miembros reciban una renta equivalente al umbral de pobreza, ha sido necesario determinar la renta que el conjunto de miembros adultos de cada hogar ha de conseguir a través del empleo, una vez descontadas aquellas fuentes de renta no ligadas al mismo. Dentro de estas últimas, ha sido preciso distinguir, por un lado, entre aquellas fuentes de renta cuyo montante recibido no habría de variar en caso de hacerlo la renta total del hogar y, por otro, aquellas que sí se habrían visto afectadas. Dentro de las primeras se han incluido tanto los planes de pensiones privados como las rentas derivadas de la posesión de activos (físicos y financieros). Aquellos hogares que declaran recibir alguna de dichas partidas no tienen que alcanzar la cantidad declarada correspondiente a través del empleo. Respecto a las segundas, diferenciamos entre, por un lado, las partidas correspondientes a pensiones alimenticias y demás ayudas familiares y, por otro, el saldo neto de impuestos abonados y transferencias públicas recibidas. En lo tocante a ayudas familiares y pensiones alimenticias, hemos calculado el nivel recibido por aquellos que se sitúan alrededor del nivel de pobreza (debido a las escasas observaciones al respecto recogidas en la muestra, consideramos los hogares situados entre el $50 \%$ y el $150 \%$ del umbral de pobreza) y hemos asignado tal cantidad exclusivamente a aquellos hogares que, efectivamente, declararon recibir alguna cantidad por esas partidas. En lo relativo a los impuestos abonados y las transferencias públicas recibidas, hemos calculado el saldo neto correspondiente a los hogares que se sitúan alrededor del umbral de pobreza y hemos asignado tal cantidad a cada hogar en función del número de adultos en el hogar y la presencia o no de hijos en el mismo. 
Los adultos presentes en cada hogar han de alcanzar, a través de su actividad laboral, la renta precisa para que cada miembro del mismo disfrute de una renta igual al umbral de pobreza equivalente, una vez descontado el montante correspondiente a las partidas precedentes. En hogares donde un único adulto participe en el empleo remunerado (bien porque sea el único adulto integrante del mismo, bien porque el otro adulto se encuentre inactivo), la responsabilidad por obtener esta renta recae enteramente sobre el mismo. En aquellos hogares con dos adultos empleados, al igual que en el caso del trabajo doméstico, la responsabilidad por obtener dicha cantidad se distribuye entre los adultos presentes en el hogar de forma proporcional a su contribución relativa a los ingresos efectivos del hogar provenientes del empleo. Una vez delimitada la cantidad de renta que cada adulto ha de obtener a través de la actividad laboral, las horas que es preciso emplear en el trabajo remunerado dependen de sus salarios respectivos. A este respecto, Goodin et al. (2005) estiman a cuánto ascendería el salario/hora al reducir las horas trabajadas en función de variables personales. En cambio, Goodin et al. (2008) y Rice, Goodin y Parpo (2006) emplean el salario efectivo, bajo la hipótesis de que, para cada combinación de salario y horas trabajadas, existirá al menos algún puesto de trabajo. En el presente trabajo, hemos optado por la segunda opción, pues la reducción temporal ha de ser pensada como si sólo fuese acometida por un individuo cada vez. De lo contrario, las implicaciones macroeconómicas adquirían tal escala que las hubiese hecho completamente imposibles de modelizar.

Finalmente, es necesario realizar dos aclaraciones. En relación con el coste del cuidado de los niños, dicha información no aparece contenida de forma explícita en las encuestas con las cuales hemos operado, por lo que hemos procedido a estimarla. Para los niños de 3 o más años, la existencia de un derecho de carácter universal a la escolarización pública conlleva que el coste necesario del cuidado de los niños es igual a 0 . Para los niños menores de 3 años, hemos procedido a estimar el coste horario del cuidado de los mismos. Seguidamente, hemos asumido que aquellos hogares con un adulto inactivo en el seno del mismo no tendrían necesidad de contratar externamente el cuidado de los niños, por lo que no tendrían que alcanzar ninguna renta adicional para su financiación. Por su parte, aquellos hogares donde todos los adultos presentes en el mismo participan en el empleo han de alcanzar a través del mismo, adicionalmente, una cantidad igual al coste horario estimado de dichos cuidados multiplicado por el tiempo necesario en el trabajo remunerado del adulto con menor magnitud en el mismo (es decir, el mínimo tiempo que el hogar ha de recurrir a los cuidados externos). Respecto a los desplazamientos desde el puesto de trabajo hacia el hogar y viceversa, hemos calculado la duración media de dicho trayecto a partir de la información contenida en la EET, y lo multiplicamos por el número de días que es preciso acudir al puesto de trabajo hasta alcanzar las horas necesarias (bajo la hipótesis de que las mismas pueden ser agrupadas en jornadas diarias estándar de 8 horas). Sumando dicha magnitud a las horas que cada adulto ha de dedicar al empleo para, con su nivel salarial actual, alcanzar para cada miembro del hogar un nivel de renta equivalente al umbral de pobreza, se ha obtenido el tiempo necesario en el trabajo remunerado para cada adulto integrante de la muestra con la cual hemos operado.

Por último, una vez calculado el tiempo necesario que cada adulto ha de dedicar, respectivamente, a los cuidados personales, el trabajo doméstico y el trabajo remunerado, el tiempo discrecional de cada uno se ha calculado sustrayendo a las 168 horas que comprenden la semana los valores correspondientes a aquellos.

\section{Tiempo discrecional $=168$ horas semanales}

menos tiempo necesario en cuidados personales menos tiempo necesario de trabajo doméstico menos tiempo necesario de trabajo remunerado

Una vez desarrollada brevemente la metodología adoptada, se procede a examinar los resultados obtenidos. En primer lugar, se abordarán las relaciones de género imperantes en la sociedad española y sus efectos en la distribución asociada del tiempo discrecional, así como los efectos derivados del tipo de hogar considerado. A continuación, se examinará, desde la perspectiva del tiempo discrecional, la relación existente entre dichas relaciones de género y la posición que los diversos agentes ocupan en el proceso productivo, es decir, se evaluarán los efectos de la intersección entre el género y la clase en relación con la autonomía temporal de la cual disfrutan los respectivos individuos.

\section{EL TIEMPO DISCRECIONAL Y LAS RELACIONES DE GÉNERO}

De forma análoga a lo señalado anteriormente con relación al tiempo libre, la distribución social del tiempo discrecional en el caso español no es inmune a las relaciones de género. El primer hecho que es necesario resaltar es que, en el agregado, las mujeres disfrutan de una menor cantidad de tiempo discrecional que los adultos varones. Este resultado es análogo al encontrado por Goodin et al. (2008: 62) en los países allí analizados (Estados Unidos, Australia, Alemania, Francia, Suecia, Finlandia). Sin embargo, importantes diferencias subyacen a la distinción por género (ver fig. 3). ${ }^{2}$ 
Figura 3.

Tiempo discrecional en función del género y la presencia de hijos

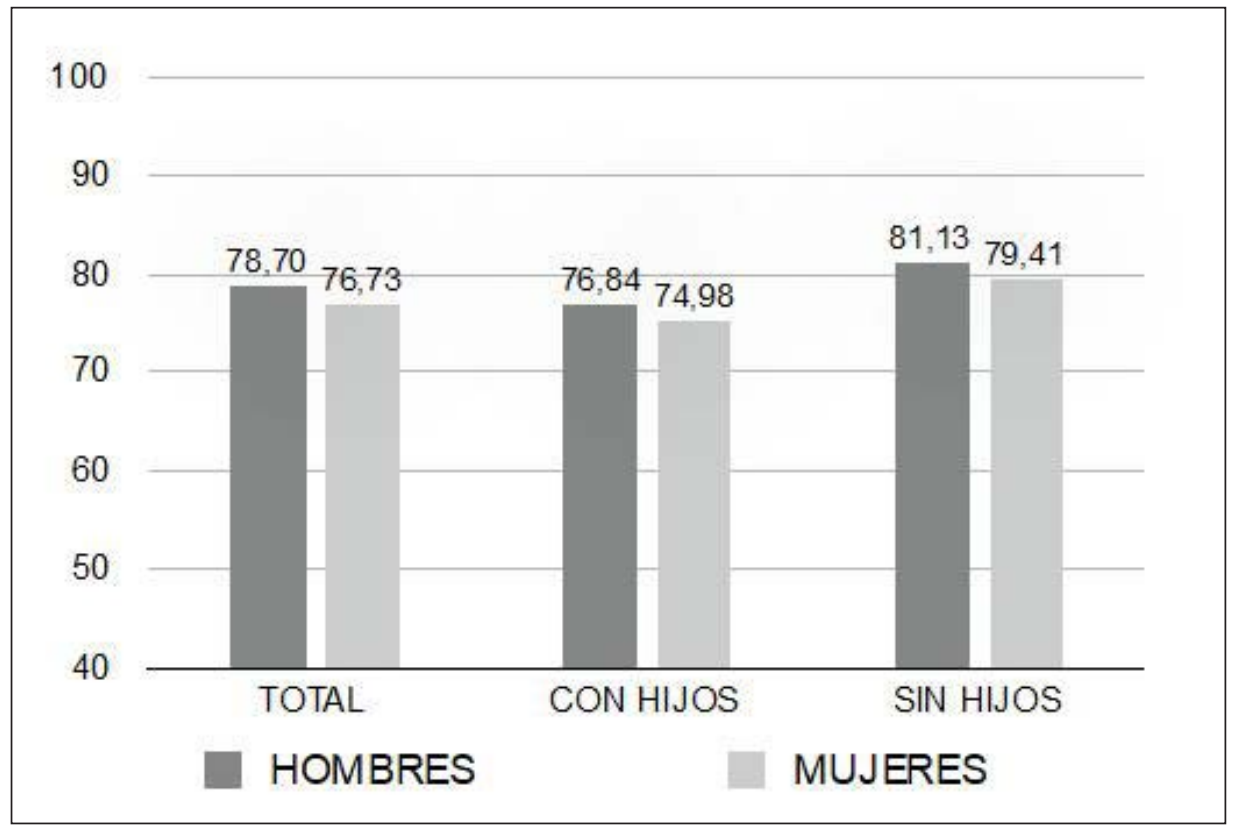

En la sociedad española, las mujeres asumen abrumadoramente las responsabilidades de cuidados, tanto respecto a los hijos como a sus mayores (Gálvez-Muñoz, Rodríguez-Modroño, y DomínguezSerrano 2011), lo cual tiene un efecto directo sobre el bienestar temporal del que disfrutan. Respecto a la presencia de hijos menores de 18 años en el hogar, dos hechos llaman primordialmente la atención. Por un lado, independientemente de la presencia o no de menores en el hogar, las mujeres disfrutan de menos tiempo discrecional que los varones integrantes de los mismos, con una diferencia de aproximadamente 2 horas semanales en ambos casos. Por otro lado, la presencia de hijos menores significa una reducción en el tiempo discrecional disponible relativamente similar para ambos sexos, ligeramente superior a las 4 horas semanales. Este hecho refleja que la presencia de hijos menores en el hogar no sólo implica necesariamente una mayor exigencia de trabajo doméstico y de cuidados, sino también que la manutención de los mismos conlleva unas exigencias mayores respecto al nivel de renta que el hogar ha de conseguir a través de la participación laboral, lo cual se traduce en una mayor cantidad de tiempo comprometido a tal efecto por los adultos implicados.

Sin embargo, pese a que este nivel de desagregación resulta ciertamente indicativo del cariz que toman las relaciones de género en la sociedad española, es conveniente explorar en mayor profundidad la naturaleza de dichas divergencias, así como aquellas internas a cada género. A continuación (ver figura 4), se presentan las respectivas magnitudes de tiempo discrecional para hombres y mujeres en función de los tres tipos de hogares que han sido considerados en el presente trabajo: hogares con un único adulto, hogares con un hombre y una mujer adultos y una única fuente de ingresos, y hogares formados por un hombre y una mujer adultos que dispongan de doble fuente de ingresos.

Como se puede observar en la figura 5 , la presencia de hijos en el hogar implica, para todos los tipos de hogar considerados, una reducción notable en el tiempo discrecional del que sus adultos disfrutan. Esta reducción presenta mayor calibre en los hogares formados por un único adulto (aproximadamente 10 horas semanales para los hombres y 15 para las mujeres), reflejando la imposibilidad de compartir la carga de dichas tareas. Aunque la diferencia entre estos y los hogares constituidos por parejas se reduce en el caso de no haber hijos menores, su magnitud sigue siendo considerable. Los adultos integrantes de parejas que disfrutan de doble fuente de ingresos parecen verse igualmente afectados por la presencia de hijos menores en el hogar, manteniéndose la divergencia en función del género en intervalos prácticamente idénticos.

Finalmente, llama la atención que, con relación a las parejas con un único ingreso laboral, la presencia de hijos en el hogar significa una reducción en el tiempo discrecional del que disfrutan los hombres tres veces superior a la experimentada por las mujeres. De hecho, las parejas con un único ingreso sin hijos son el único tipo en el cual las mujeres disfrutan de significativamente más tiempo discrecional que los hombres (en el caso de los hogares con un adulto sin hijos, la diferencia es positiva, aunque in- 
Figura 4.

Tiempo discrecional en función del género, la presencia de hijos y el tipo de hogar

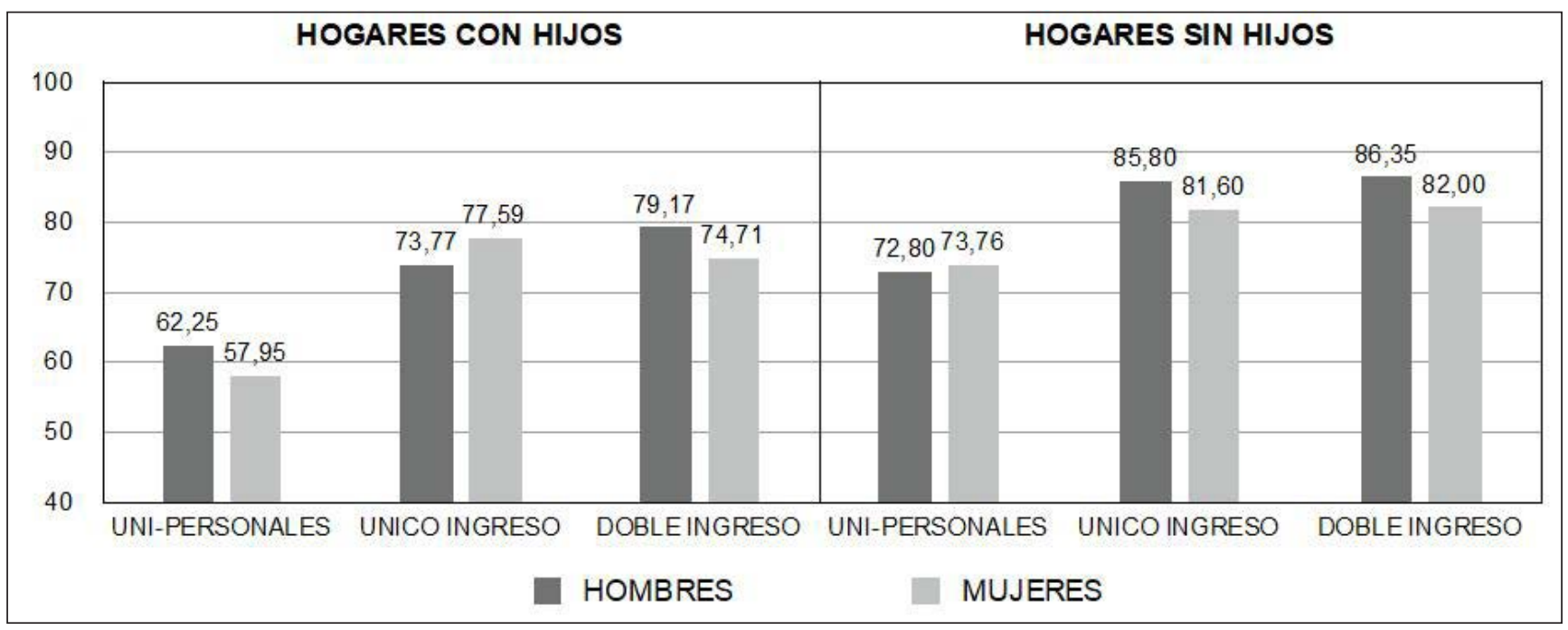

ferior a una hora semanal). A priori podría semejar una parcial reversión de los patrones tradicionales en torno al uso y autonomía sobre los tiempos en este particular tipo de hogar. Sin embargo, cuando se observan los valores correspondientes a hombres y mujeres diferenciando si, respectivamente, se corresponden con el adulto que participa en el empleo o bien con el adulto inactivo laboralmente, la mayor autonomía de las mujeres al respecto se torna una ilusión. Por lo tanto, dicho resultado, anómalo solamente en apariencia, se debe a que en dichos hogares los adultos que no participan en la actividad laboral son en su mayoría mujeres, lo cual se plasma en una mayor magnitud de tiempo discrecional correspondiente a las mujeres en el agregado. Sin embargo, tal y como se aprecia en la figura 5, cuando son las mujeres las que se encuentran empleadas estas disfrutan de aproximadamente 10 horas menos de tiempo discrecional que los hombres que se encuentran igualmente empleados en dichos hogares. Esto se debe a que deben gastar una parte significativa de su tiempo obteniendo ingresos monetarios en el mercado, pero también a que siguen conservando primordialmente las responsabilidades de cuidados. En el caso de disponer de hijos menores en el hogar, el tiempo comprometido, se trate de hombre o mujer, incrementa, pero el gender gap permanece inalterado.

Figura 5.

Tiempo discrecional en familias con un único ingreso

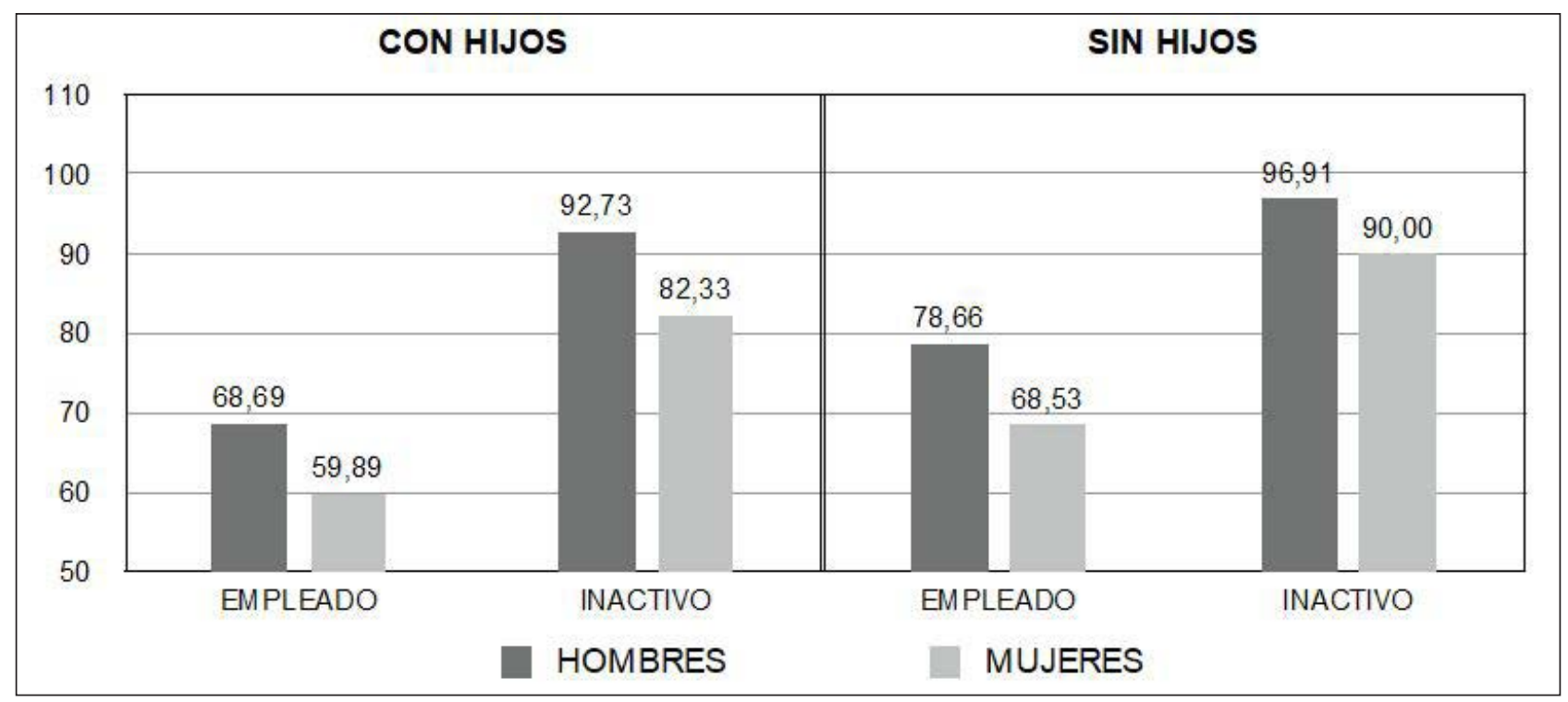

RIS [online] 2019, 77 (1), e119. REVISTA INTERNACIONAL DE SOCIOLOGÍA. ISSN-L: 0034-9712 
En relación con el miembro laboralmente inactivo de la pareja, la diferencia respecto al miembro empleado es significativa para ambos sexos, alrededor de las 20 horas semanales dependiendo del caso concreto. Cabe destacar que, aunque la diferencia de género parece operar con menor intensidad en relación al miembro inactivo en caso de ausencia de hijos menores en el hogar, sigue siendo significativa, aproximadamente de 7 horas semanales por término medio.

A raíz del análisis presentado en el presente apartado podemos extraer al menos tres conclusiones. En primer lugar, se observa una marcada divergencia en torno al género respecto a la autonomía de la cual los adultos disponen sobre su propio tiempo. Estos resultados entroncan con los obtenidos en la literatura respecto a la ubicuidad de las asimétricas relaciones de género en el contexto español. En segundo lugar, aunque las relaciones de género actúan de forma transversal, el tipo de hogar que los adultos habitan, en función tanto del número de personas incluidas en el mismo como de la presencia o ausencia de hijos menores, afecta significativamente a su autonomía temporal. Las responsabilidades de cuidados asociadas a los distintos tipos de hogar considerados varían significativamente y, en consecuencia, también la autonomía temporal disfrutada por los adultos pertenecientes a los mismos. En tercer lugar, la presencia de hijos menores en el hogar reduce invariablemente el tiempo discrecional de sus adultos, aunque de forma desigual. Las parejas con doble fuente de ingresos se ven comparativamente menos afectados en su autonomía temporal por la presencia de hijos pequeños en el hogar, reflejando el hecho de que disponer de doble fuente de ingresos, por un lado, les exige emplear menos tiempo en el mercado laboral para alcanzar un nivel de subsistencia y, por otro, les permite externalizar parcialmente sus responsabilidades de cuidados. La otra cara de la moneda la representan los hogares formados por un único adulto con hijos en el hogar, donde la imposibilidad de repartir las responsabilidades aparejadas los sitúa como un grupo singularmente vulnerable en relación con su bienestar temporal, por lo que deberían convertirse en objetivos prioritarios de unas políticas públicas que, con los datos presentes, parecen ser harto incapaces de ofrecer a los mismos unas condiciones equivalentes a las disfrutadas por el resto de hogares considerados.

\section{INTERSECCIONES ENTRE EL GÉNERO Y LA CLASE SOCIOECONÓMICA}

Como indicamos anteriormente, junto a la fractura social en torno al género la sociedad española presenta importantes divergencias en su seno en función del lugar que ocupan sus integrantes (tanto personas como hogares) en el proceso productivo.
De manera análoga a la forma en que ambos procesos de segmentación se reflejan en las desiguales distribuciones de renta y riqueza, cabría pensar que dichos procesos tuvieran a su vez un reflejo tanto en los usos del tiempo como en la disponibilidad del mismo. Un candidato obvio para cumplir esa función sería el tiempo libre. Sin embargo, mientras que efectivamente las divergencias existentes en torno al género quedan patentes en la distribución del tiempo libre en función de aquel, los resultados obtenidos con relación a la clase socioeconómica de los individuos no resultan en absoluto concluyentes. La relación entre clase socioeconómica y tiempo libre no muestra un sentido unívoco, siendo este dependiente en última instancia de las variables concretas a partir de las cuales se determine la primera. Como indicamos anteriormente, esta aparente paradoja se debe a que la cantidad declarada de tiempo libre no refleja ningún criterio de necesidad $u$ obligatoriedad subyacente, sino que, al contrario, se corresponde con una elección concreta dentro de un abanico de posibilidades más amplio. Por lo tanto, no es posible asociar la distribución poblacional resultante con otra análoga referida al bienestar individual, pues, más allá de las controversias teóricas generadas al respecto, resulta difícil sostener que aquellas personas que ocupan los eslabones más bajos en los ordenamientos sociales imperantes estén sujetas a los mismos imperativos y necesidades que aquellos que disfrutan de posiciones más acomodadas en los mismos. Esta divergencia entre estricta necesidad, por un lado, y elección individual, por otro, es precisamente la que la metodología del tiempo discrecional aspira a desenmascarar. A continuación, se presentan los resultados obtenidos sobre la distribución del tiempo discrecional en función de diversos indicadores, a partir de los cuales resulta razonable inferir la clase socioeconómica de origen, con el objetivo de desentrañar hasta qué punto el bienestar temporal es una realidad ajena a las relaciones de clase o $\mathrm{si}$, por el contrario, aquel se encuentra fuertemente sobredeterminado por estas.

\section{a) Nivel Educativo}

Anteriormente fue observado cómo el nivel educativo alcanzado parecía presentar una relación inversa con el tiempo libre disfrutado por los individuos en un día promedio. Estos resultados parecen confirmar la hipótesis de Gershuny (2005), según la cual se observaría una relación inversa entre el estatus social y el tiempo libre o sin ocupar. Si empleamos el tiempo discrecional en lugar del tiempo libre para evaluar la disponibilidad temporal, sin embargo, los resultados obtenidos son los opuestos. Es decir, tal y como se observa en la figura 6, la magnitud de tiempo discrecional disponible para cada adulto se incrementa unívocamente conforme el nivel educativo alcanzado crece. 
Figura 6.

Tiempo discrecional en función del nivel educativo alcanzado

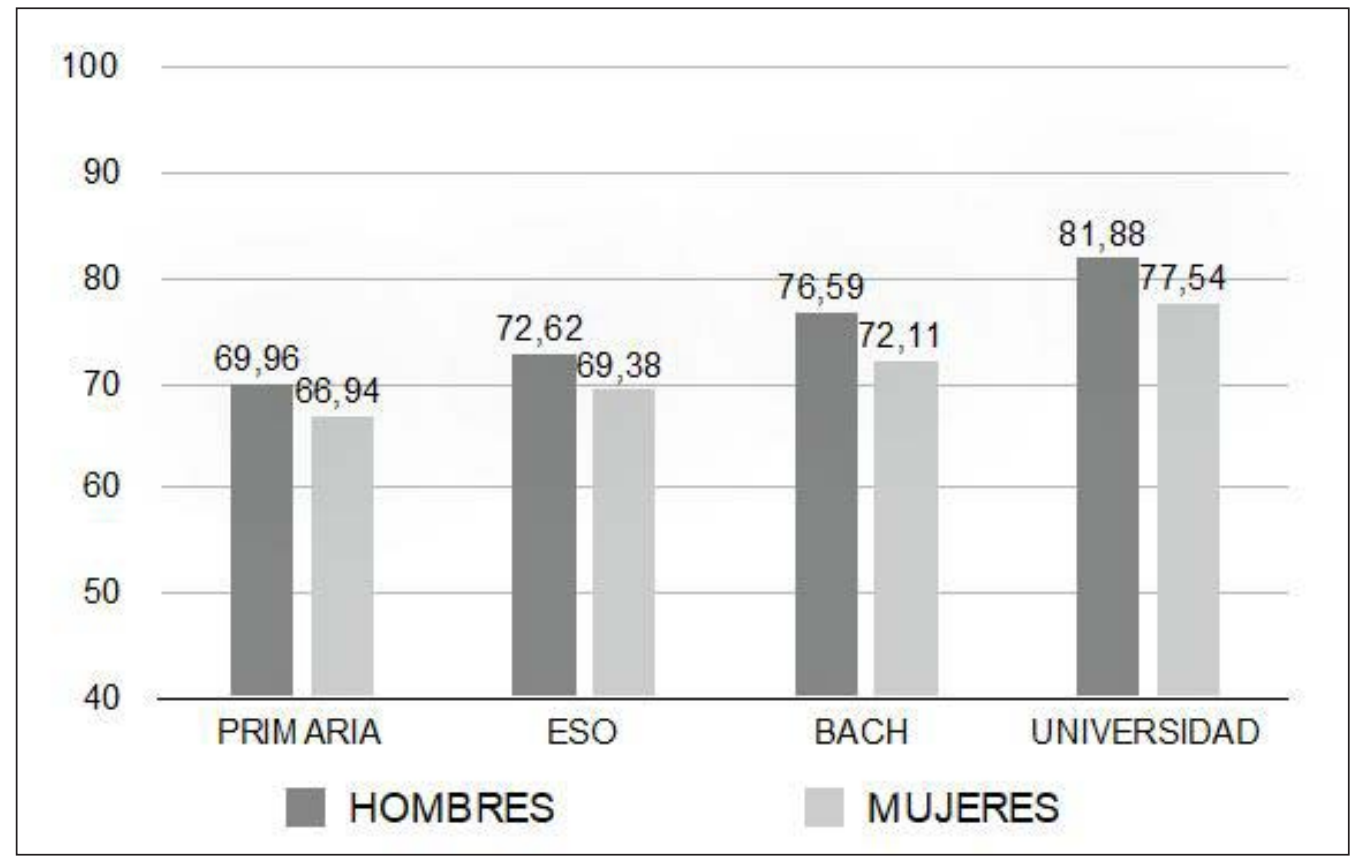

Estos resultados cuestionan la validez de los estudios que emplean el tiempo libre como magnitud para medir el bienestar temporal de los individuos. Aunque aquellos con estudios primarios declaren disponer de más tiempo de ocio que aquéllos con estudios universitarios, difícilmente puede ser argumentado, a la luz de los datos presentados, que se ven igualmente sometidos a las demandas de la estricta necesidad de garantizarse la mera subsistencia.

En lo tocante a las relaciones de género subyacentes, tanto para los hombres como para las mujeres el tiempo discrecional se ve incrementado conforme aumenta el nivel educativo, manteniéndose la distancia entre los géneros relativamente constante. Sin embargo, si distinguimos las familias que tienen hijos de los hogares que no, observamos que la fractura de género evoluciona de forma distinta en relación con el nivel educativo (ver figura 7). La presencia de hijos en el hogar hace que la distancia entre hombres y mujeres se mantenga relativamente constante, mientras que, para las parejas sin hijos, la distancia se incrementa notablemente conforme es mayor el nivel educativo alcanzado, lo cual explica el paulatino incremento en el agregado al cual hacíamos anteriormente mención. Mientras que para aquellos con estudios primarios la diferencia es mínima (menos de una hora semanal), aquellos con estudios universitarios muestran un gender gap prácticamente idéntico a los adultos universitarios con hijos.

\section{b) Actividad económica de la empresa}

El modelo productivo imperante en la economía española desde mediados de la década de 1990 se ha caracterizado por mostrar una marcada sobrees-
Figura 7.

Gender gap en el tiempo discrecional en relación con el nivel educativo

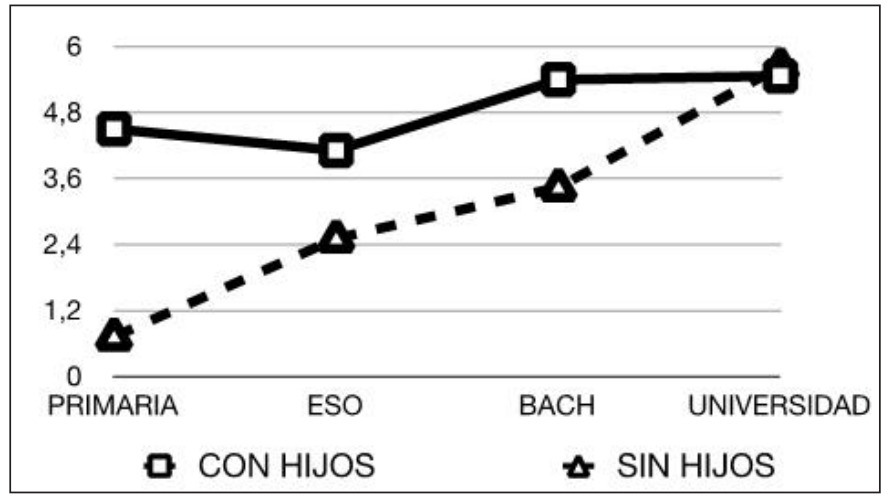

pecialización en sectores de muy bajo contenido tecnológico, principalmente la construcción y el turismo. Dichos sectores han experimentado los crecimientos más pronunciados en sus respectivos volúmenes de empleo, caracterizado por bajos salarios y altos niveles de temporalidad. En contraposición al segmento externo del mercado laboral, encontramos otras ocupaciones caracterizadas por más altos salarios y cualificaciones requeridas, así como mayores niveles de seguridad en el empleo. A continuación, presentamos la distribución de tiempo discrecional para ambos sexos, considerando cuatro sectores representativos del mercado laboral español. Por un lado, construcción y turismo, ramas en las cuales la economía española se encuentra sobreespecializada, caracterizadas por bajos salarios, bajas cualificaciones requeridas y baja seguridad en el empleo; $y$, por otro, los sectores de 
educación y actividades financieras, representantes arquetípicos de los mercados internos o primarios de trabajo (Doeringer y Piore 1985), caracterizados por mayores niveles salariales, de competencias requeridas y estabilidad en el puesto de trabajo. Por lo tanto, la elección de dichos sectores económicos en el caso español pretende incorporar las diferencias de clase existentes en el interior del modelo productivo español a través de los niveles de cualificación, así como la naturaleza de las tareas requeridas generalmente por dichos sectores.

De nuevo, las diferencias en términos de tiempo discrecional entre los adultos que participan en sectores representativos de los segmentos primario y secundario del mercado laboral, respectivamente, son notables (ver figura 8). Por un lado, tanto la hostelería como la construcción tienden a ofrecer peores condiciones laborales y peor remuneración que los otros dos sectores considerados, lo que se traduce en un inferior bienestar temporal disfrutado por aquellos que participan en dichos sectores. Llama la atención la situación de las mujeres que trabajan en el sector de la construcción, pues disfrutan de niveles de tiempo discrecional superiores a los hombres del mismo sector, a escasa distancia de las mujeres pertenecientes al sector educativo o al de las finanzas. Esto se explica porque el sector de la construcción es un sector económico altamente masculinizado, en el cual las mujeres que en él participan no desarrollan generalmente ocupaciones estrictamente manuales. Por el otro lado, tanto el sector de las finanzas como el educativo tienden a ofrecer mejores condiciones laborales, bien sea por el mayor nivel de cualificación requerido, bien por el mayor nivel de representación sindical con el que estos sectores cuentan. Sin embargo, en ningún caso son homogéneos entre sí. Mientras que el primero tiende a ofrecer mayor re- muneración salarial en contrapartida por mayores niveles de exigencia horaria, el segundo tiende a compaginar horarios más benevolentes con el resto de tiempos sociales con un menor nivel salarial. Como indicábamos anteriormente, al tomar simultáneamente en consideración variables de índole temporal y monetaria en una métrica común, la metodología del tiempo discrecional ofrece una aproximación más compleja a la problemática del bienestar individual. Desde la perspectiva de la autonomía temporal, los mejores salarios de uno se tornan equivalentes con los mayores niveles retributivos del otro, emergiendo así con mayor claridad las dinámicas de polarización social asociadas al modelo productivo español, las cuales no corren necesariamente en paralelo con aquellas identificadas en análisis restringidos a variables de naturaleza monetaria o temporal.

\section{c) Tipo de ocupación}

De forma similar al epígrafe inmediatamente anterior, empleamos el tipo de ocupación en el puesto de trabajo principal como variable aproximativa de la clase socioeconómica, con el objetivo de evaluar las divergencias al respecto del tiempo discrecional en torno a aquella. Con base en la Clasificación Nacional de Ocupaciones (CNO-1994), seleccionamos dos ocupaciones a priori asociadas con altos salarios, elevada seguridad en el empleo y altos niveles de cualificación requeridos (Dirección de las Empresas y de la Administración Pública -Grupo 1-y Técnicos y Profesionales Científicos e Intelectuales -Grupo 2-); y otras dos asociadas con bajos salarios y cualificaciones y reducida seguridad en el empleo (Trabajadores de Servicios de Restauración, Personales, Protección y Vendedores de los Comercios -Grupo 5- y Trabajadores No Cualificados -Grupo 9-).

Figura 8.

Tiempo discrecional en relación con el sector de actividad de la empresa

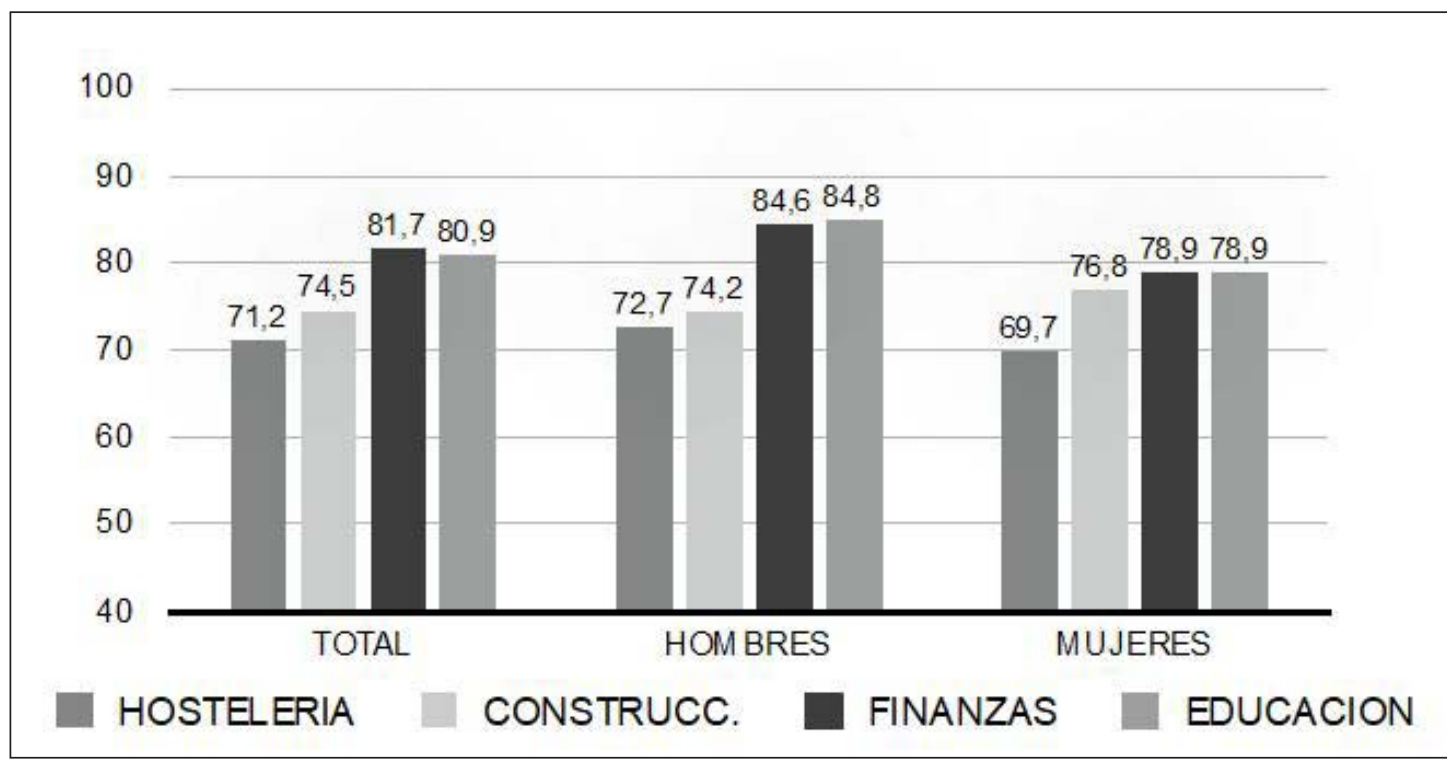


Figura 9.

Tiempo discrecional en relación con el tipo de ocupación

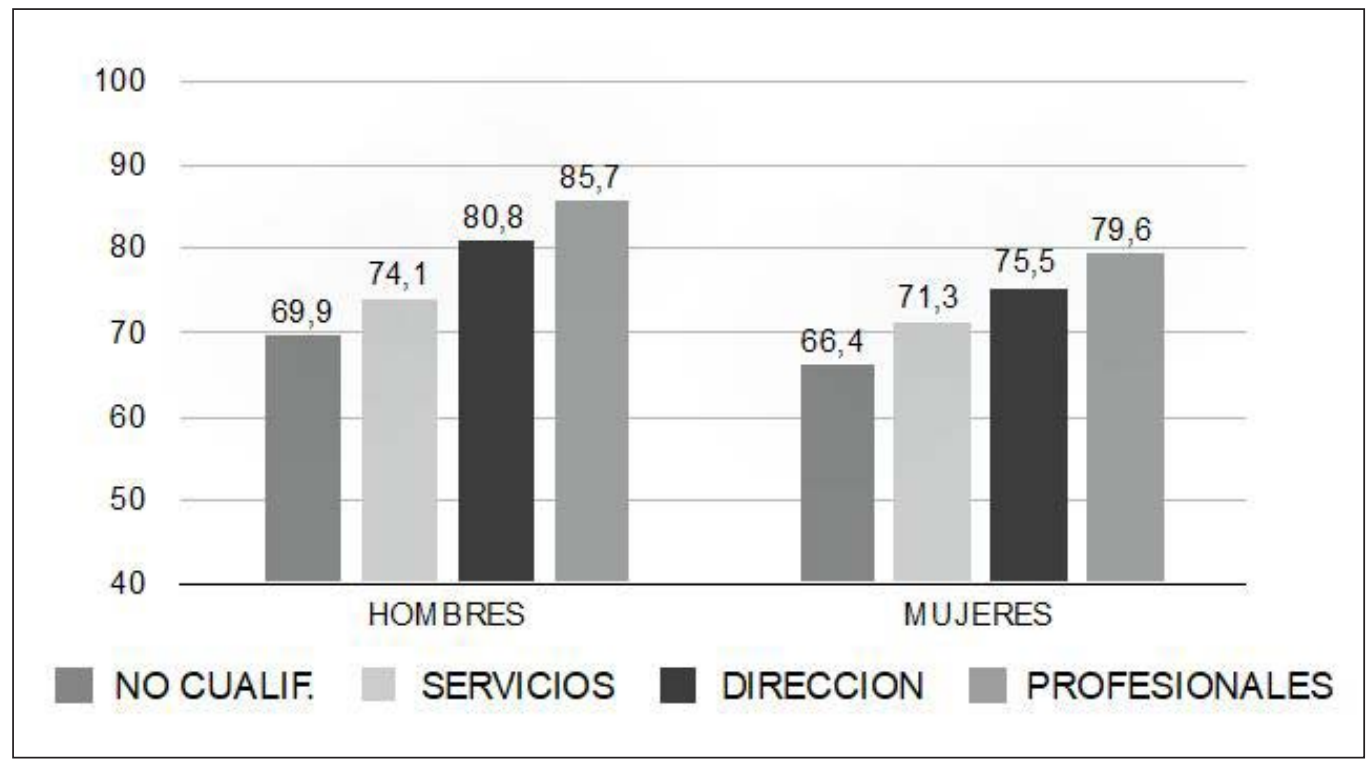

Aunque el análisis de las ocupaciones laborales ofrece una forma necesariamente imperfecta a través de la cual aproximarnos a la clase socioeconómica de origen, se observa, de nuevo, que los patrones distributivos resultantes guardan estrecha relación con los obtenidos en los dos epígrafes anteriores (ver figura 9). Por un lado, las mujeres disfrutan sistemáticamente de menos tiempo discrecional que los hombres para los cuatro grandes grupos de ocupaciones considerados. Por otro lado, se observa que el tiempo discrecional de aquellos que detentan ocupaciones asociadas con mejores condiciones laborales y remuneración disfrutan efectivamente de un grado mayor de discrecionalidad sobre su propio tiempo. Al igual que respecto al sector de actividad del empleador, no es posible establecer ningún tipo de relación lineal entre los grupos seleccionados para el análisis.

Resultaría interesante, ciertamente, poder ofrecer un análisis con un mayor grado de desagregación de las clasificaciones ocupacionales. Pese a que la ECV incluye un nivel de detalle de dos dígitos, tal y como figura en la CNO-94, el limitado tamaño muestral con el que trabajamos previene su uso. Asimismo, habría resultado interesante ofrecer un análisis que tuviese en cuenta la naturaleza de las tareas desarrolladas en el empleo distinguiendo, por ejemplo, entre aquellos que desempeñan mayoritariamente tareas rutinarias y no rutinarias, mas la ausencia de información al respecto en la ECV sitúa dicho ejercicio fuera del alcance del presente trabajo.

Como indicábamos en la introducción, ningún estudio hasta la fecha ha adoptado la metodología del tiempo discrecional para evaluar los efectos sobre la autonomía temporal de las relaciones de clase sub- yacentes, por lo que no podemos ofrecer una comparación internacional de los resultados obtenidos al respecto. Sin embargo, los resultados obtenidos sí permiten arrojar nueva luz sobre las dinámicas de polarización internas del modelo de crecimiento español de las últimas décadas. Las tres rutas a través de las cuales hemos tratado de aproximar las relaciones de clase arrojan invariablemente dos resultados. Por un lado, las mujeres disfrutan sistemáticamente de un menor grado de discrecionalidad sobre su propio tiempo que los hombres, independientemente de la posición concreta que ocupen en el proceso productivo. De esta forma, el presente estudio contribuye a la extensa literatura existente sobre las relaciones de género en España, ofreciendo una nueva perspectiva teórica sobre las penalizaciones que de aquellas se derivan sobre el bienestar disfrutado por las mujeres, tanto temporal como monetario. Por otro lado, el presente análisis concluye que las relaciones de clase juegan un papel fundamental en la atribución asimétrica de responsabilidades por reproducir un orden social, corriendo las diferencias resultantes en torno a la autonomía y bienestar temporales, en paralelo a aquellas más comúnmente estudiadas con relación a la renta y/o riqueza monetarias.

\section{Conclusión}

El modelo de crecimiento español, en el curso de su evolución durante las dos últimas décadas, ha generado nuevas fuentes de desigualdad a la par que ha exacerbado otras ya existentes. Este artículo ha empleado la metodología del tiempo discrecional con el objetivo de arrojar nueva luz sobre la dimensión temporal de las desigualdades que dicho modelo ha consolidado. En concreto, el foco ha recaído sobre 
las intersecciones entre las relaciones de género, las características del hogar y la clase socioeconómica.

El tiempo libre declarado por los individuos permite entrever diferencias en torno al género, mas no permite establecer una relación unívoca respecto a la clase socioeconómica a la cual pertenecen los individuos. Con el objetivo de desentrañar las diferentes presiones de índole temporal a las que se ven sometidos los individuos en función de su inclusión diferencial en el modelo productivo, hemos examinado la distribución del tiempo discrecional en una semana promedio en función del género, el tipo de hogar y diversos indicadores que nos permiten considerar la clase socioeconómica. En primer lugar, los resultados obtenidos nos permiten corroborar la existencia de una sistemática discriminación hacia las mujeres, relativa a la autonomía temporal que disfrutan. Para la práctica totalidad de las situaciones consideradas, las mujeres gozan de menos tiempo discrecional que los hombres en circunstancias análogas. En segundo lugar, observamos que el tipo de hogar y, en particular, la presencia de hijos menores en el mismo, constituye un factor fundamental para comprender las divisiones existentes en torno al tiempo discrecional del cual gozan los adultos que en él habitan, situándose, en algunos casos, como más importante que los otros vectores de segmentación considerados. En tercer lugar, se observa que, tanto para hombres como para mujeres, la clase socioeconómica está relacionada positivamente con la autonomía temporal que disfrutan. Sea aquella determinada a través del nivel educativo alcanzado, el sector económico en el cual están empleados o el tipo de trabajo que realizan, los resultados obtenidos muestran invariablemente una menor autonomía temporal para quienes ocupan los eslabones más bajos en el orden social y productivo imperante en la sociedad española actual.

\section{NotAs}

1. Goodin et al. incluyen un minucioso apéndice metodológico donde figuran todas las operaciones necesarias para calcular las diversas magnitudes que aquí se presentan. Remitimos al mismo al lector interesado en una explicación más detallada que la que aquí, por motivos de espacio, se ofrece (Goodin et al. 2008: 271-325)

\section{REFERENCIAS BibLIOGRÁFICAS}

Banyuls, J., F. Miguélez, A. Recio, E. Cano, y R. Lorente. 2009. "The Transformation of the Employment System in Spain: Towards a Mediterranean Neoliberalism?". Pp. 247-269 en European Employment Models in Flux. A Comparison of Institutional Change in Nine European Countries, editado por G. Bosch, S. Lehndorff, y J. Rubery. Londres: Palgrave Macmillan.

Bittman, M. 2011. "II) Goodin et al.'s New Measure of Freedom: Authors Meet Critic". Social Indicators Research 101 (2): 185-187. (https://doi.org/10.1007/s11205-010-9651-2)

Bowles, S. y Y. Park. 2005. "Emulation, Inequality, and Work Hours: Was Thorsten Veblen Right?". The Economic Journal 115 (507): 397-412. https://doi.org/10.1111/ j.1468-0297.2005.01042.x

Callejo, J. y C. Prieto. 2015. "Distribución y Organización de Los Tiempos de Trabajo, Cuidados y Ocio Con Una Perspectiva de Género". Pp. 53-86 en Trabajo, Cuidados, Tiempo Libre y Relaciones de Género en la Sociedad Española, editado por C. Prieto. Madrid: CINCA.

Doeringer, P. y M. Piore. 1985. Mercados Internos de Trabajo y Análisis Laboral. Madrid: Servicio de Publicaciones del Ministerio de Trabajo y Seguridad Social.

Esping-Andersen, G. 1990. The Three Worlds of Welfare Capitalism. Oxford: Polity Press.

Esping-Andersen, G. 1999. Social Foundations of Postindustrial Economies. Oxford: Oxford University Press. https://doi.org/10.1093/0198742002.001.0001

Ferrera, M. 1996. 'The 'Southern Model' of Welfare in Social Europe". Journal of European Social Policy 6 (1): 1737. https://doi.org/10.1177/095892879600600102
2. Aunque la convención en los estudios sobre usos del tiempo es presentar los resultados en términos de un día promedio, no es así en los estudios relativos al tiempo discrecional por lo que, en los gráficos que siguen, los resultados se presentan en términos de una semana promedio, con el objetivo de facilitar la comparación con los resultados ya obtenidos para otros países.

Freeman, R. y L. Bell. 2001. "The Incentive for Working Hard: Explaining Hours Worked Differences in the US and Germany". Labour Economics Special Conference Volume 8 (2): 181-202. https://doi.org/10.1016/S09275371(01)00030-6

Gálvez-Muñoz, L., P. Rodríguez-Modroño y M. DomínguezSerrano. 2011. "Work and Time Use By Gender: A New Clustering of European Welfare Systems". Feminist Economics 17 (4): 125-57. https://doi.org/10.1080/13 545701.2011 .620975

Gershuny, J. 2000. Changing Times: Work and Leisure in Postindustrial Society. Oxford: Oxford University Press.

Gershuny, J. 2005. "Busyness as the Badge of Honor for the New Superordinate Working Class". Social Research, 72 (2): 287-314.

Gimenez-Nadal, J. y A. Sevilla. 2011. "The Time-Crunch Paradox". Social Indicators Research 102 (2): 181-196. https://doi.org/10.1007/s11205-010-9689-1

Gimenez-Nadal, J. y A. Sevilla. 2014. "Total Work Time in Spain: Evidence from Time Diary Data". Applied Economics 46 (16): 1894-1909. https://doi.org/10.1080/00 036846.2014 .887194

Gómez Serrano, P., R. Molero Simarro y L. Buendía. 2016. "The Impact of the 2008/9 Crisis on Inequality and Poverty in Southern Europe: The Case of Spain". Journal of Australian Political Economy 78: 87-114.

Goodin, R., J. Rice M. Bittman y P. Saunders. 2005. "The TimePressure Illusion: Discretionary Time vs. Free Time". Social Indicators Research 73 (1): 43-70. https://doi. org/10.1007/s11205-004-4642-9 
Goodin, R., J. Rice, A. Parpo y L. Eriksson. 2008. Discretionary Time. A New Measure of Freedom. New York: Cambridge University Press. https://doi.org/10.1017/ CBO9780511611452

Goodin, R., J. Rice, A. Parpo y L. Eriksson. 2011. "III) Discretionary Time: A Rejoinder". Social Indicators Research 101 (2): 189-192. https://doi.org/10.1007/s11205-010-9652-1

Instituto Nacional de Estadística. 2011a. Encuesta de Empleo del Tiempo, 2009-10.

Instituto Nacional de Estadística. 2011b. Encuesta de Condiciones de Vida, 2010.

Karamessini, M. 2008. "Still a Distinctive Southern European Employment Model?". Industrial Relations Journal 39 (6): 510-531. https://doi.org/10.1111/j.14682338.2008.00503.x

Prieto, C. 2015. Trabajo, Cuidados, Tiempo Libre y Relacions de Género en la Sociedad Española. Madrid: CINCA.

Prieto, C. y S. Perez de Guzmán. 2013. "Desigualdades Laborales de Género, Disponibilidad Temporal y Normatividad Social". Revista Española de Investigaciones Sociológicas 141: 113-32.
Rey-Araújo, P. 2016. "La Reducción del Tiempo de Trabajo en la Actual Crisis Orgánica: Una Propuesta desde el Post-Marxismo y la Economía Política Radical". Revista de Economía Crítica 21: 75-92.

Rice, J., R. Goodin y A. Parpo. 2006. "The Temporal Welfare State: A Crossnational Comparison". Journal of Public Policy 26 (3): 195-228. https://doi.org/10.1017/ S0143814X06000523

Saraceno, C. 1994. "The Ambivalent Familism of the Italian Welfare State". Social Politics 1 (1): 60-82. https://doi. org/10.1093/sp/1.1.60

Schor, J. 1994. La Excesiva Jornada Laboral en Estados Unidos: La Inesperada Disminución del Tiempo de Ocio. Madrid: Servicio de Publicaciones del Ministerio de Trabajo y Seguridad Social.

Shippen, N. M. 2014. Decolonizing Time. Work, Leisure, and Freedom. New York: Palgrave Macmillan.

Veblen, T. 2004. Teoría de la Clase Ociosa. Madrid: Alianza Editorial.

PEDRO M. REY ARAÚJO es investigador pre-doctoral en la Universidade de Santiago de Compostela. En la actualidad se encuentra completando su investigación doctoral en torno a la dimensión temporal del modelo de acumulación español. Sus intereses académicos abarcan la economía política, el estudio del mercado laboral y la sociología del tiempo.

MELCHOR FERNÁNDEZ FERNÁNDEZ (Universidad Autónoma de Barcelona, doctor en Economía, 1999) es profesor titular en el Departamento de Fundamentos del Análisis Económico en la Universidade de Santiago de Compostela, así como exdirector del Instituto de Desenvolvemento de Galicia (IDEGA). Sus áreas de investigación comprenden temas relacionados con el mercado laboral, el desarrollo económico y la aplicación de modelos de equilibrio general al sector turístico. 